\title{
Cannabidiol enhances anandamide signaling and alleviates psychotic symptoms of schizophrenia
}

\author{
FM Leweke ${ }^{1,2}$, D Piomelli ${ }^{3,4}$, F Pahlisch ${ }^{1,3}$, D Muhl ${ }^{2,3}$, CW Gerth ${ }^{2}$, C Hoyer ${ }^{1,2}$, J Klosterkötter $^{2}$, M Hellmich ${ }^{5}$ and D Koethe ${ }^{1,2}$
}

Cannabidiol is a component of marijuana that does not activate cannabinoid receptors, but moderately inhibits the degradation of the endocannabinoid anandamide. We previously reported that an elevation of anandamide levels in cerebrospinal fluid inversely correlated to psychotic symptoms. Furthermore, enhanced anandamide signaling let to a lower transition rate from initial prodromal states into frank psychosis as well as postponed transition. In our translational approach, we performed a double-blind, randomized clinical trial of cannabidiol vs amisulpride, a potent antipsychotic, in acute schizophrenia to evaluate the clinical relevance of our initial findings. Either treatment was safe and led to significant clinical improvement, but cannabidiol displayed a markedly superior sideeffect profile. Moreover, cannabidiol treatment was accompanied by a significant increase in serum anandamide levels, which was significantly associated with clinical improvement. The results suggest that inhibition of anandamide deactivation may contribute to the antipsychotic effects of cannabidiol potentially representing a completely new mechanism in the treatment of schizophrenia.

Translational Psychiatry (2012) 2, e94; doi:10.1038/tp.2012.15; published online 20 March 2012

\section{Introduction}

The search for safe and effective drugs to treat schizophrenia is hindered by the complex nature of this disorder, which is known to involve multiple brain neurotransmitters. ${ }^{1}$ Among them are the endogenous cannabinoids, a family of lipid messengers that target the same cell surface receptors engaged by $\Delta^{9}$-tetrahydrocannabinol in marijuana. ${ }^{2}$ Because $\Delta^{9}$-tetrahydrocannabinol and other direct-acting cannabinoid agonists can induce psychotic symptoms both in healthy volunteers $^{3-5}$ and schizophrenic patients, ${ }^{6,7}$ it has been suggested that hyperactivity of the endocannabinoid system might contribute to psychotic states. ${ }^{8,9}$ This idea has fueled two large-scale clinical trials with $\mathrm{CB}_{1}$-type cannabinoid receptor antagonists in schizophrenia, which yielded, however, negative results. ${ }^{10,11} \mathrm{~A}$ diametrically opposite view namely that certain components of the endocannabinoid system might have a protective role in schizophrenia - was suggested by studies with antipsychotic-naïve schizophrenic patients, in which it was found that the symptom intensity experienced by these subjects was negatively correlated with cerebrospinal levels of anandamide, ${ }^{12,13}$ an endocannabinoid transmitter known to be involved in the regulation of pain, mood and cognition. ${ }^{14}$ Consistent with these clinical observations, animal experiments have shown that pharmacological blockade of anandamide degradation attenuates, rather than enhances, psychotic-like behaviors induced in rodents by amphetamine and phencyclidine. ${ }^{15,16}$

Cannabidiol is a non-psychotropic component of marijuana that binds to $\mathrm{CB} 1$ receptors with only comparably very low affinity ${ }^{17,18}$ and is devoid of overt cannabimimetic or propsychotic properties. ${ }^{17}$ Biochemical studies indicate that cannabidiol may enhance endogenous anandamide signaling indirectly, by inhibiting the intracellular degradation of anandamide catalyzed by the enzyme fatty acid amide hydrolase (FAAH).$^{19}$ Furthermore, preliminary clinical case reports suggest that cannabidiol might exert antipsychotic effects in schizophrenic patients. ${ }^{20-22}$ In addition, experimental studies show that cannabidiol reduces psychosis-like effects of $\Delta^{9}$-tetrahydrocannabinol and synthetic analogs. ${ }^{22,23}$

\section{Materials and methods}

\section{Pre-clinical studies}

Detection of fatty acid ethanolamides. Serum levels of anandamide, palmityolethanolamide and oleoylethanolamide were determined at baseline, day 14 and day 28 by liquid chromatography/mass spectrometry as described previously. ${ }^{24,25}$

FAAH assay. FAAH activity was measured at $37^{\circ} \mathrm{C}$ for $30 \mathrm{~min}$ in $0.5 \mathrm{ml}$ of Tris buffer $(50 \mathrm{mM}, \mathrm{pH} 7.5)$ containing fatty acid-free bovine serum albumin $(0.05 \%, \mathrm{w} / \mathrm{v})$, protein from tissue homogenates of the rat brain membranes $(50 \mu \mathrm{g})$, cannabidiol $(0.3 \mu \mathrm{M}, 1 \mu \mathrm{M}, 3 \mu \mathrm{M}, 10 \mu \mathrm{M}, 30 \mu \mathrm{M}, 0.3 \mathrm{~mm}, 0.1 \mathrm{~mm}$, and $1 \mathrm{~mm})$ and $\left({ }^{3} \mathrm{H}\right.$-ethanolamine) anandamide (10000 d.p.m., specific activity $20 \mathrm{Ci} \mathrm{mmol}^{-1}$ ). For concentration response the drug CBD was dissolved in dimethyl sulfoxide and added to the samples at a final concentration of $1 \%$ dimethyl

\footnotetext{
${ }^{1}$ Department of Psychiatry and Psychotherapy, Central Institute of Mental Health, Medical Faculty Mannheim, Heidelberg University, Mannheim, Germany; ${ }^{2}$ Department of Psychiatry and Psychotherapy, University of Cologne, Cologne, Germany; ${ }^{3}$ Department of Pharmacology and Biological Chemistry, University of California, Irvine, CA, USA; ${ }^{4}$ The Unit of Drug Discovery and Development, Italian Institute of Technology, Genova, Italy and ${ }^{5}$ Institute for Medical Statistics, Informatics, and Epidemiology, University of Cologne, Cologne, Germany

Correspondence: Professor FM Leweke, Department of Psychiatry and Psychotherapy, Central Institute of Mental Health, University of Heidelberg, Medical Faculty Mannheim, J5, 68159 Mannheim, Germany or D Piomelli, Department of Pharmacology and Biological Chemistry, University of California, Irvine, 3101 Gillespie Neuroscience Facility, Irvine, CA 91697-4625, USA.

E-mail: leweke@cimh.de or piomelli@uci.edu

Keywords: anandamide; cannabidiol; endocannabinoid; fatty acid amide hydrolase; human; schizophrenia

Received 13 October 2011; revised 9 January 2012; accepted 30 January 2012
} 
sulfoxide. The reactions were stopped with chloroform/ methanol $(1: 1,1 \mathrm{ml})$, and radioactivity was measured in the aqueous layers by liquid scintillation counting.

Clinical trial. This study was a therapeutic-exploratory (phase II), double-blinded, monocenter, randomized, parallel-group, controlled clinical trial of cannabidiol vs amisulpride (CBD-CT1; ClinicalTrials.gov. Identifier: NCT00628290). The study protocol was approved by the Ethics Committee of the University of Cologne and the BfArM (Federal Institute for Drugs and Medical Products). Initially an independent psychiatrist assessed patients to confirm their ability to provide informed consent. Then, written informed consent was obtained from each patient following a detailed explanation of study procedures.

Men and women age 18-50 years who had a diagnosis of schizophrenia or schizophreniform psychosis according to the DSM-IV criteria were eligible for the study. All patients were hospitalized at baseline and through day 28 after random assignment to treatment. A total number of 42 inpatients of the Department of Psychiatry and Psychotherapy of the University of Cologne participated in the study. In all, 37 patients were suffering from acute paranoid schizophrenia (DSM-IV 295.30). Another 5 patients were initially diagnosed as suffering from schizophreniform psychosis (DSM-IV 295.40) based on the duration of illness, but were followed-up and diagnosed with paranoid schizophrenia after completing the study. Only acutely psychotic patients with a total Brief Psychiatric Rating Scale (BPRS) score $\geqslant 36$ and a BPRS THOT factor (thought disorders) score $\geqslant 12$ were eligible to participate. Patients with a positive urine drug screening for illicit drugs in general and cannabinoids in particular were not allowed to participate to avoid an interaction of currently bioactive cannabinoids (including cannabidiol) with treatment. Further exclusion criteria were relevant psychiatric disorders including substance use disorders, previous treatment with a depot antipsychotic within 3 months before the participation in the study, a history of treatment resistance, defined by the persistence of severe symptoms despite adequate treatment with at least two antipsychotics or prior treatment with clozapine, a relevant and/or unstable medical condition and an insufficient contraception, pregnancy or breast-feeding in female patients.

We enrolled 42 acutely exacerbated schizophrenic patients who had met the DSM-IV criteria. In all, 39 patients were evaluated according to modified intention-to-treat (Table 1), 33 were observed and treated per protocol and all 42 were valid for safety evaluation (Figure 1). After a screening period of up to 7 days and a minimum period of 3 antipsychoticfree days patients were randomized (1:1) to receive either cannabidiol or amisulpride starting with $200 \mathrm{mg}$ per day each and increased stepwise by $200 \mathrm{mg}$ per day to a daily dose of $200 \mathrm{mg}$ four times daily (total $800 \mathrm{mg}$ per day) each within the first week. The hospital pharmacy provided individual medication kits according to a randomization sequence prepared by a person otherwise not involved in the study (drawing paper lots out of a bowl). The respective treatment was maintained for another 3 weeks. A reduction of each treatment to $600 \mathrm{mg}$ per day was allowed for clinical reasons, such as unwanted side effects after week 2 , which was the case for three patients in the cannabidiol and five patients in the amisulpride treatment
Table 1 Baseline description of full analysis set (modified intention-to-treat)

\begin{tabular}{|c|c|c|c|}
\hline & $\begin{array}{c}\text { Cannabidiol } \\
(\mathrm{n}=20)\end{array}$ & $\begin{array}{c}\text { Amisulpride } \\
(\mathrm{n}=19)\end{array}$ & $\mathrm{P}$-value \\
\hline \multicolumn{4}{|c|}{ Demographic characteristics, mean (s.d.) } \\
\hline Age, years & $29.7(8.3)$ & $30.6(9.4)$ & 0.966 \\
\hline Weight, kg & $81.8(16.0)$ & $73.3(11.4)$ & 0.106 \\
\hline Pulse, beats/min & $83.4(12.7)^{\mathrm{b}}$ & $86.3(14.2)$ & 0.490 \\
\hline \multicolumn{4}{|c|}{ Blood pressure, $\mathrm{mm} \mathrm{Hg}$} \\
\hline Diastolic & $80.8(9.2)$ & $77.3(7.1)$ & 0.224 \\
\hline Systolic & $123.8(15.5)$ & $119.2(13.1)$ & 0.394 \\
\hline $\begin{array}{l}\text { Male gender, } \\
\text { count }(\%)\end{array}$ & $15(75)$ & $17(89)$ & 0.407 \\
\hline \multicolumn{4}{|c|}{$\begin{array}{l}\text { Baseline severity of illness scores, mean (s.d.) } \\
\text { PANSS }\end{array}$} \\
\hline $\begin{array}{l}\text { PANSS } \\
\text { Total }\end{array}$ & $91.2(14.0)$ & $95.5(17.1)$ & 0.736 \\
\hline Positive & $24.6(5.6)$ & $22.5(6.2)$ & 0.205 \\
\hline Negative & $23.7(5.4)$ & $25.3(5.6)$ & 0.573 \\
\hline General & $42.9(8.6)$ & $47.7(11.4)$ & 0.155 \\
\hline Factor 1 & $16.3(4.8)$ & $15.9(5.6)$ & 0.554 \\
\hline Factor 2 & $20.2(4.8)$ & $21.8(5.3)$ & 0.516 \\
\hline Factor 3 & $10.0(2.6)$ & $11.2(3.4)$ & 0.134 \\
\hline Factor 4 & $12.6(2.7)$ & $11.8(4.1)$ & 0.592 \\
\hline Factor 5 & $10.0(4.0)$ & $10.7(3.4)$ & 0.489 \\
\hline BPRS & $58.1(9.7)$ & $57.7(10.3)$ & 0.746 \\
\hline CGI severity & $6.3(0.7)$ & $6.8(0.4)$ & 0.011 \\
\hline \multicolumn{4}{|l|}{ Other, mean (s.d.) } \\
\hline Lorazepam, mg/day & $2.2(1.6)$ & $4.2(2.4)$ & 0.006 \\
\hline SAS & $36.4(7.7)$ & $36.9(8.1)$ & 0.800 \\
\hline EPS & $0.1(0.2)$ & $0.0(0.1)$ & 0.485 \\
\hline
\end{tabular}

Abbreviations: BPRS, Brief Psychiatric Rating Scale; CGI, Clinical Global Impression Scale; EPS, Extrapyramidal Symptoms Rating Scale; PANSS, Positive and Negative Syndrome Scale; SAS, Social Anxiety Scale. ${ }^{\text {a T}}$ The Wicoxon rank sum test or Fisher's exact test. ${ }^{b} n=19$.

Bold indicates statistical significance between groups $(P \leqslant 0.05)$.

group. In addition, lorazepam co-medication was allowed with up to $7.5 \mathrm{mg}$ per day during the entire study.

Clinical measurements. The end points of the clinical trials are generally accepted and recommended by the European Medicines Agency for the measurement of clinically observed changes in patients with an acute schizophrenic and schizophreniform psychosis. The BPRS and the Positive and Negative Syndrome Scale (PANSS) were both used as primary outcome measures for the assessment of psychotic symptoms at baseline, day 14 and day 28 of the treatment period of the trial. The BPRS was implemented in the trial to establish a fast to assess safety parameter in case of a relevant worsening of symptoms in single patients and was assessed on day 7 and day 21 if clinically relevant by investigator's decision. Side effects were evaluated using the Extrapyramidal Symptom Scale (EPS) and included the measurement of serum prolactin $\left(\mu \mathrm{gl}^{-1}\right)$ and body weight $(\mathrm{kg})$. Safety measures included repeated electrocardiograms as well as routine blood parameters.

Hypotheses and statistical analysis. The primary study objective was to determine whether cannabidiol given for 28 days was non-inferior to amisulpride in the treatment of patients with schizophrenia as measured by the PANSS and the BPRS. Side effects were evaluated using the Extrapyramidal Symptom Scale and included the measurement of serum prolactin $\left(\mu \mathrm{gl}^{-1}\right)$ and body weight $(\mathrm{kg})$. Safety 


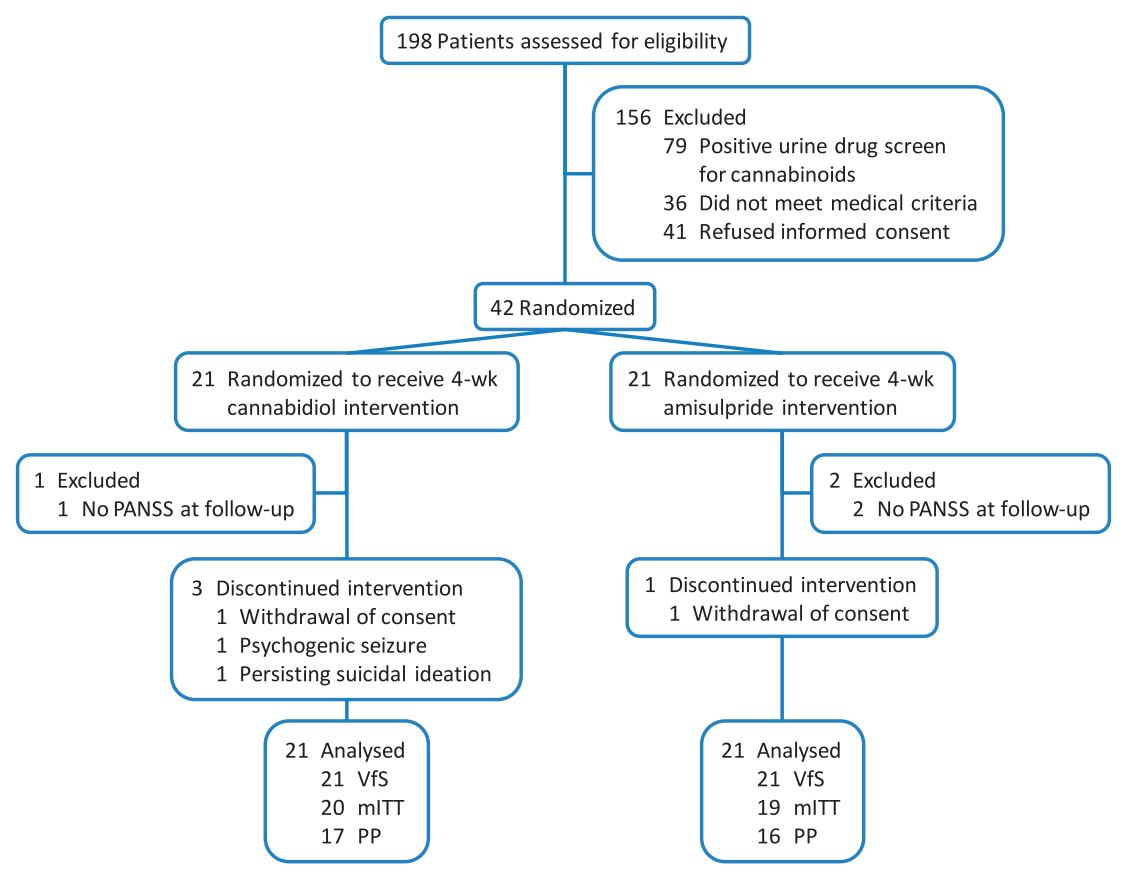

Figure 1 Participant flow; analysis sets: VfS, valid for safety; mITT, modified intention-to-treat and PP, per protocol.

measures included repeated electrocardiograms as well as routine blood values. These end points are generally accepted and recommended by the European Medicines Agency for the measurement of clinically observed changes in patients with an acute schizophrenic and schizophreniform psychosis.

We planned to randomly assign 35 patients to each treatment group which would have provided $82 \%$ power to detect an effect size of $0.7(\approx 9 / 13=\Delta / \sigma)$ in the change-frombaseline PANSS/BPRS total score at a two-sided $5 \%$ significance level using an unadjusted two-sample $t$-test. ${ }^{26}$ Unfortunately, enrolment was significantly affected by the exclusion of cannabinoid-positive patients in urine drug screening (Figure 1), which led to a termination of the study due to expiration of funding.

The primary efficacy variable was the intra-individual difference of PANSS and BPRS at baseline (days -8 to -1 ) and day 28, that is, PANSS/BPRS (baseline) minus PANSS/ BPRS (day 28). The primary hypothesis to be tested confirmatory with the parametric Sasabuchi test, $(\alpha=2.5 \%$, one-sided) was relevant inferiority of cannabidiol vs amisulpride, that is, $H_{0}: \mu_{\text {Cannabidiol }-} \theta \cdot \mu_{\text {Amisulpride }} \leq 0$ vs $H_{1}$ : $\mu_{\text {Cannabidiol }}-\theta \cdot \mu_{\text {Amisulpride }}>0$ with $\theta=80 \%$ ( $\mu$ denotes the expected value). ${ }^{27}$ Equivalently, a 95\% confidence interval for the ratio $\mu_{\text {Cannabidiol }} / \mu_{\text {Amisulpride }}$ was calculated (according to Fieller). The non-inferiority parameter $\theta=80 \%$ was chosen because in the literature PANSS/BPRS changes of $20-50 \%$ are discussed as 'response to therapy'. ${ }^{28}$ Thus, changes up to $20 \%$ can be deemed clinically irrelevant (especially because of the large intra-individual variance; compare CPMP/EWP, 1998). ${ }^{29}$

Patients with missing post baseline measures were excluded from the efficacy analysis. Thus, the 'modified intention-to-treat' set encompassed all patients who had been randomized, had received any study medication and had provided a valid PANSS/BPRS at day 14 or 28. A missing PANSS/BPRS at day 28 was imputed by the last valid preceding value 'last observation carried forward', LOCF. The 'per protocol' set encompassed all patients who had been treated, and observed according to protocol.

A mixed effects repeated measures model (unstructured covariance matrix) for the change-from-baseline included baseline as a covariate with treatment, visit and treatment-byvisit interaction as fixed effects (missing values were not imputed). The same analysis model was chosen for secondary outcomes and side effects. Specific contrasts were evaluated (between groups at specific visits, between visits within groups).

The 'valid for safety' set encompassed all patients who were randomized and received any study medication. On the basis of this the treatment-emergent adverse events were compared among treatment groups using Fisher's exact test. Owing to the exploratory nature of the study, all analyses were performed without adjustment for multiplicity. Statistical analyses were done using IBM SPSS Statistics 19 (Somers, NY, USA) and R 2.12.1 (Vienna, Austria; Sasabuchi test, Fieller's confidence interval).

\section{Results}

The basic hypothesis for our translational approach was that enhancement of anandamide signaling by administration of cannabidiol should result in an improvement of psychotic symptoms. To put this hypothesis to test, we performed a 4-week double-blind, parallel-group, randomized, active-controlled clinical trial of cannabidiol vs the 

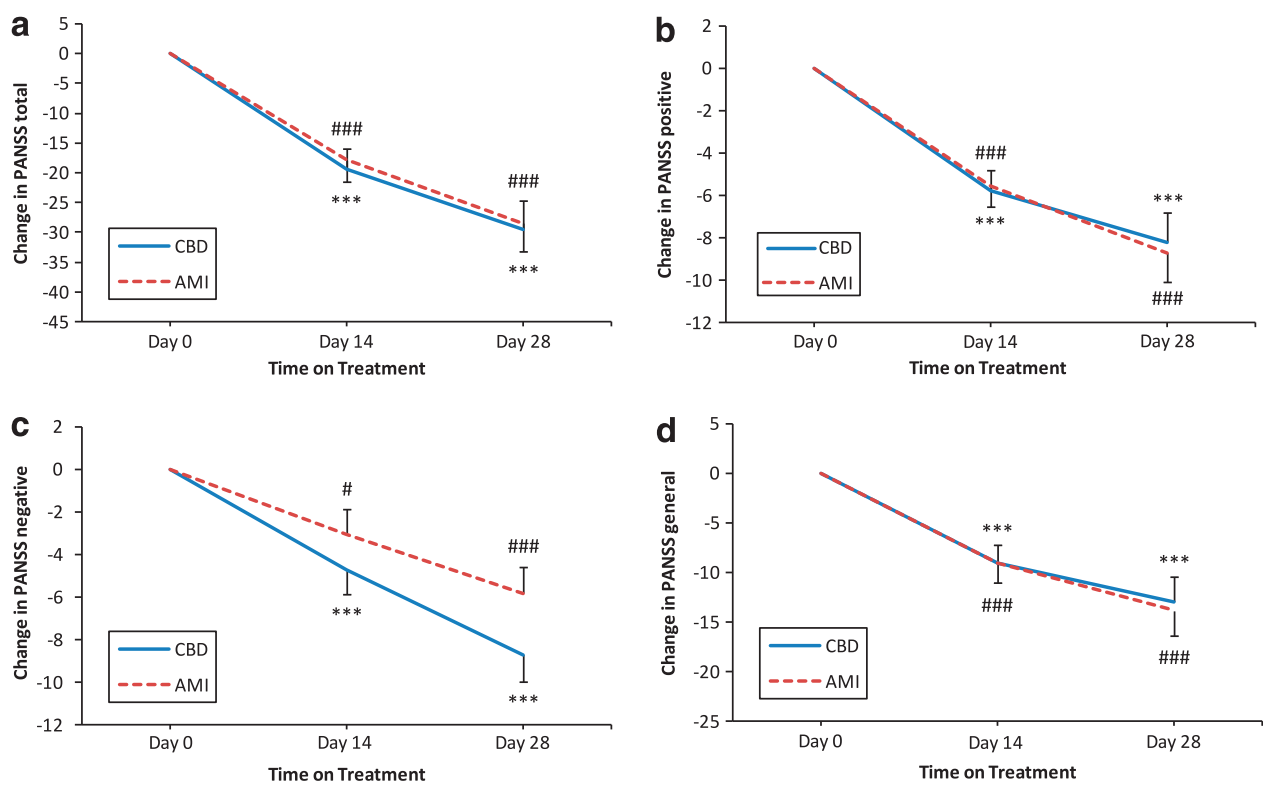

Figure 2 Changes from baseline in Positive and Negative Symptoms Scale (PANSS) scores determined using mixed effects repeated measures model analysis (adjusted for baseline). (a) PANSS total score. (b) PANSS-positive score. (c) PANSS-negative score. (d) PANSS general score. Data show predicted means and s.e. at each weak. Statistical significance is calculated between groups $\left({ }^{\dagger} P \leqslant 0.05,{ }^{\dagger \dagger} P \leqslant 0.01\right.$ and ${ }^{\dagger \dagger \dagger} P \leqslant 0.001$ ) and vs baseline (that is, 0 ; ${ }^{*} \mathrm{CBD},{ }^{\#} \mathrm{AMl} ;{ }^{* * * / \# \# \#} P \leqslant 0.05,{ }^{* * / \# \#} P \leqslant 0.01$, $\left.{ }^{\star / \#} P \leqslant 0.001\right)$.

Table 2 Changes in PANSS and BPRS, descriptive statistics and MMRM results adjusted for baseline, full analysis set (modified intention-to-treat)

\begin{tabular}{|c|c|c|c|c|c|c|c|c|c|}
\hline & \multirow[b]{2}{*}{$\begin{array}{l}\text { Baseline } \\
\text { to (day) }\end{array}$} & \multicolumn{3}{|c|}{ Cannabidiol } & \multicolumn{3}{|c|}{ Amisulpride } & \multicolumn{2}{|c|}{ Cannabidiol vs Amisulpride } \\
\hline & & $\begin{array}{l}\text { Mean } \\
\text { (s.d., n) }\end{array}$ & $\begin{array}{c}E M M \\
\text { (s.e., df) }\end{array}$ & P-value & $\begin{array}{c}\text { Mean } \\
(s . d ., n)\end{array}$ & $E M M$ (s.e., df) & P-value & $\begin{array}{l}\text { Difference } \\
(95 \% \mathrm{Cl}, \mathrm{df})\end{array}$ & P-valu \\
\hline $\begin{array}{l}\text { PANSS } \\
\text { Total }\end{array}$ & $\begin{array}{l}14 \\
28\end{array}$ & $\begin{array}{l}18.8(10.7,20) \\
30.5(16.4,17)\end{array}$ & $\begin{array}{l}19.4(3.4,36.1) \\
29.5(4.7,34.3)\end{array}$ & $\begin{array}{l}<0.001 \\
<0.001\end{array}$ & $\begin{array}{l}18.8(19.9,19) \\
30.1(24.7,18)\end{array}$ & $\begin{array}{l}17.9(3.5,36.1) \\
28.5(4.7,32.6)\end{array}$ & $\begin{array}{l}<0.001 \\
<0.001\end{array}$ & $\begin{array}{l}1.5(-8.5 \text { to } 11.5,36.1) \\
1.0(-12.6 \text { to } 14.6,33.7)\end{array}$ & $\begin{array}{l}0.763 \\
0.884\end{array}$ \\
\hline Positive & $\begin{array}{l}14 \\
28\end{array}$ & $\begin{array}{l}6.3(4.7,20) \\
9.0(6.1,17)\end{array}$ & $\begin{array}{l}5.8(1.0,36.0) \\
8.2(1.4,34.3)\end{array}$ & $\begin{array}{l}<0.001 \\
<0.001\end{array}$ & $\begin{array}{l}5.1(5.0,19) \\
8.4(7.5,18)\end{array}$ & $\begin{array}{l}5.5(1.0,36.0) \\
8.7(1.4,33.2)\end{array}$ & $\begin{array}{l}<0.001 \\
<0.001\end{array}$ & $\begin{array}{r}0.2(-2.6 \text { to } 3.0,36.1) \\
-0.5(-4.5 \text { to } 3.5,33.8)\end{array}$ & $\begin{array}{l}0.878 \\
0.800\end{array}$ \\
\hline Negative & $\begin{array}{l}14 \\
28\end{array}$ & $\begin{array}{l}4.5(4.6,20) \\
9.1(4.9,17)\end{array}$ & $\begin{array}{l}4.7(1.1,36.4) \\
8.7(1.3,32.5)\end{array}$ & $\begin{array}{l}<0.001 \\
<0.001\end{array}$ & $\begin{array}{l}3.3(5.9,19) \\
6.4(6.0,18)\end{array}$ & $\begin{array}{l}3.0(1.1,36.4) \\
5.8(1.3,30.9)\end{array}$ & $\begin{array}{l}0.012 \\
<0.001\end{array}$ & $\begin{array}{l}1.7(-1.6 \text { to } 5.0,36.5) \\
2.9(-0.8 \text { to } 6.6,31.9)\end{array}$ & $\begin{array}{l}0.300 \\
0.116\end{array}$ \\
\hline General & $\begin{array}{l}14 \\
28\end{array}$ & $\begin{array}{c}8.0(5.4,20) \\
12.5(10.4,17)\end{array}$ & $\begin{array}{r}9.0(1.8,35.9) \\
12.9(2.5,33.1)\end{array}$ & $\begin{array}{l}<0.001 \\
<0.001\end{array}$ & $\begin{array}{l}10.4(11.4,19) \\
15.3(14.3,18)\end{array}$ & $\begin{array}{r}9.1(1.9,35.9) \\
13.9(2.5,31.1)\end{array}$ & $\begin{array}{l}<0.001 \\
<0.001\end{array}$ & $\begin{array}{l}-0.1(-5.4 \text { to } 5.2,36.0) \\
-0.9(-8.2 \text { to } 6.4,32.5)\end{array}$ & $\begin{array}{l}0.975 \\
0.799\end{array}$ \\
\hline Factor 1 & $\begin{array}{l}14 \\
28\end{array}$ & $\begin{array}{l}3.0(4.7,20) \\
4.8(5.0,17)\end{array}$ & $\begin{array}{l}2.8(0.8,36.0) \\
4.1(1.2,30.1)\end{array}$ & $\begin{array}{l}<0.001 \\
0.002\end{array}$ & $\begin{array}{l}3.3(5.3,19) \\
4.6(7.7,18)\end{array}$ & $\begin{array}{l}3.3(0.8,36.0) \\
4.5(1.2,28.5)\end{array}$ & $\begin{array}{l}<0.001 \\
<0.001\end{array}$ & $\begin{array}{l}-0.5(-2.7 \text { to } 1.7,36.0) \\
-0.4(-3.9 \text { to } 3.1,29.3)\end{array}$ & $\begin{array}{l}0.658 \\
0.812\end{array}$ \\
\hline Factor 2 & $\begin{array}{l}14 \\
28\end{array}$ & $\begin{array}{l}3.1(4.1,20) \\
8.0(4.5,17)\end{array}$ & $\begin{array}{l}3.4(1.0,35.9) \\
7.6(1.2,30.9)\end{array}$ & $\begin{array}{l}0.002 \\
<0.001\end{array}$ & $\begin{array}{l}3.2(5.2,19) \\
6.0(6.1,18)\end{array}$ & $\begin{array}{l}2.9(1.0,35.9) \\
5.5(1.2,29.5)\end{array}$ & $\begin{array}{l}0.008 \\
<0.001\end{array}$ & $\begin{array}{l}0.4(-2.5 \text { to } 3.4,36.0) \\
2.2(-1.2 \text { to } 5.6,30.4)\end{array}$ & $\begin{array}{l}0.776 \\
0.203\end{array}$ \\
\hline Factor 3 & $\begin{array}{l}14 \\
28\end{array}$ & $\begin{array}{l}2.5(2.0,20) \\
3.2(2.5,17)\end{array}$ & $\begin{array}{l}2.7(0.5,36.1) \\
3.3(0.7,35.5)\end{array}$ & $\begin{array}{l}<0.001 \\
<0.001\end{array}$ & $\begin{array}{l}1.7(3.1,19) \\
3.4(3.4,18)\end{array}$ & $\begin{array}{l}1.4(0.5,36.2) \\
3.2(0.7,33.5)\end{array}$ & $\begin{array}{l}0.011 \\
<0.001\end{array}$ & $\begin{array}{l}1.2(-0.3 \text { to } 2.8,36.2) \\
0.1(-1.8 \text { to } 2.0,35.0)\end{array}$ & $\begin{array}{l}0.107 \\
0.922\end{array}$ \\
\hline Factor 4 & $\begin{array}{l}14 \\
28\end{array}$ & $\begin{array}{l}3.2(2.4,20) \\
5.2(2.5,17)\end{array}$ & $\begin{array}{l}3.1(0.6,36.0) \\
4.7(0.8,35.5)\end{array}$ & $\begin{array}{l}<0.001 \\
<0.001\end{array}$ & $\begin{array}{l}3.2(2.9,19) \\
5.1(4.2,18)\end{array}$ & $\begin{array}{l}3.3(0.6,36.0) \\
5.2(0.8,33.8)\end{array}$ & $\begin{array}{l}<0.001 \\
<0.001\end{array}$ & $\begin{array}{l}-0.2(-1.9 \text { to } 1.4,36.0) \\
-0.5(-2.7 \text { to } 1.7,34.7)\end{array}$ & $\begin{array}{l}0.778 \\
0.647\end{array}$ \\
\hline Factor 5 & $\begin{array}{l}14 \\
28\end{array}$ & $\begin{array}{l}2.0(2.7,20) \\
3.0(4.4,17)\end{array}$ & $\begin{array}{l}2.1(0.5,35.6) \\
3.3(0.7,29.1)\end{array}$ & $\begin{array}{l}<0.001 \\
<0.001\end{array}$ & $\begin{array}{l}2.9(3.0,19) \\
4.1(3.5,18)\end{array}$ & $\begin{array}{l}2.7(0.6,35.6) \\
3.8(0.7,27.3)\end{array}$ & $\begin{array}{l}<0.001 \\
<0.001\end{array}$ & $\begin{array}{l}-0.5(-2.1 \text { to } 1.1,35.6) \\
-0.5(-2.6 \text { to } 1.7,28.2)\end{array}$ & $\begin{array}{l}0.511 \\
0.659\end{array}$ \\
\hline \multicolumn{10}{|l|}{ BPRS } \\
\hline & $\begin{array}{l}7 \\
14 \\
21 \\
28\end{array}$ & $\begin{array}{c}6.4(6.1,20) \\
14.5(7.9,20) \\
18.4(10.6,16) \\
20.5(12.3,17)\end{array}$ & $\begin{array}{r}6.4(1.8,35.8) \\
14.5(2.2,35.5) \\
16.9(2.8,35.4) \\
18.9(3.2,33.7)\end{array}$ & $\begin{array}{l}<0.001 \\
<0.001 \\
<0.001 \\
<0.001\end{array}$ & $\begin{array}{c}7.9(9.5,19) \\
12.7(12.0,19) \\
14.2(14.4,18) \\
19.4(15.6,18)\end{array}$ & $\begin{array}{r}8.0(1.8,35.8) \\
12.8(2.2,35.5) \\
14.0(2.8,33.0) \\
19.1(3.1,32.0)\end{array}$ & $\begin{array}{l}<0.001 \\
<0.001 \\
<0.001 \\
<0.001\end{array}$ & $\begin{array}{l}-1.6(-6.7 \text { to } 3.5,35.8) \\
1.7(-4.6 \text { to } 8.1,35.5) \\
2.9(-5.1 \text { to } 10.9,34.2) \\
-0.1(-9.2 \text { to } 8.9,32.8)\end{array}$ & $\begin{array}{l}0.530 \\
0.589 \\
0.468 \\
0.977\end{array}$ \\
\hline
\end{tabular}

Abbreviations: BPRS, Brief Psychiatric Rating Scale; Cl, confidence interval; df, degrees of freedom; EMM, estimated marginal mean; MMRM, mixed effects repeated measures model; PANSS, Positive and Negative Syndrome Scale.

Bold indicates statistical significance between groups $(P \leqslant 0.05)$.

dopamine $D_{2} / D_{3}$-receptor antagonist amisulpride-one of the most effective drugs currently in use for the treatment of schizophrenia. ${ }^{30}$ Patients undergoing either cannabidiol or amisulpride treatment showed significant clinical improvement, assessed by the reduction in PANSS total score $(P<0.001$, day 28 vs day 0 , Figure 2 a) as well as for all 

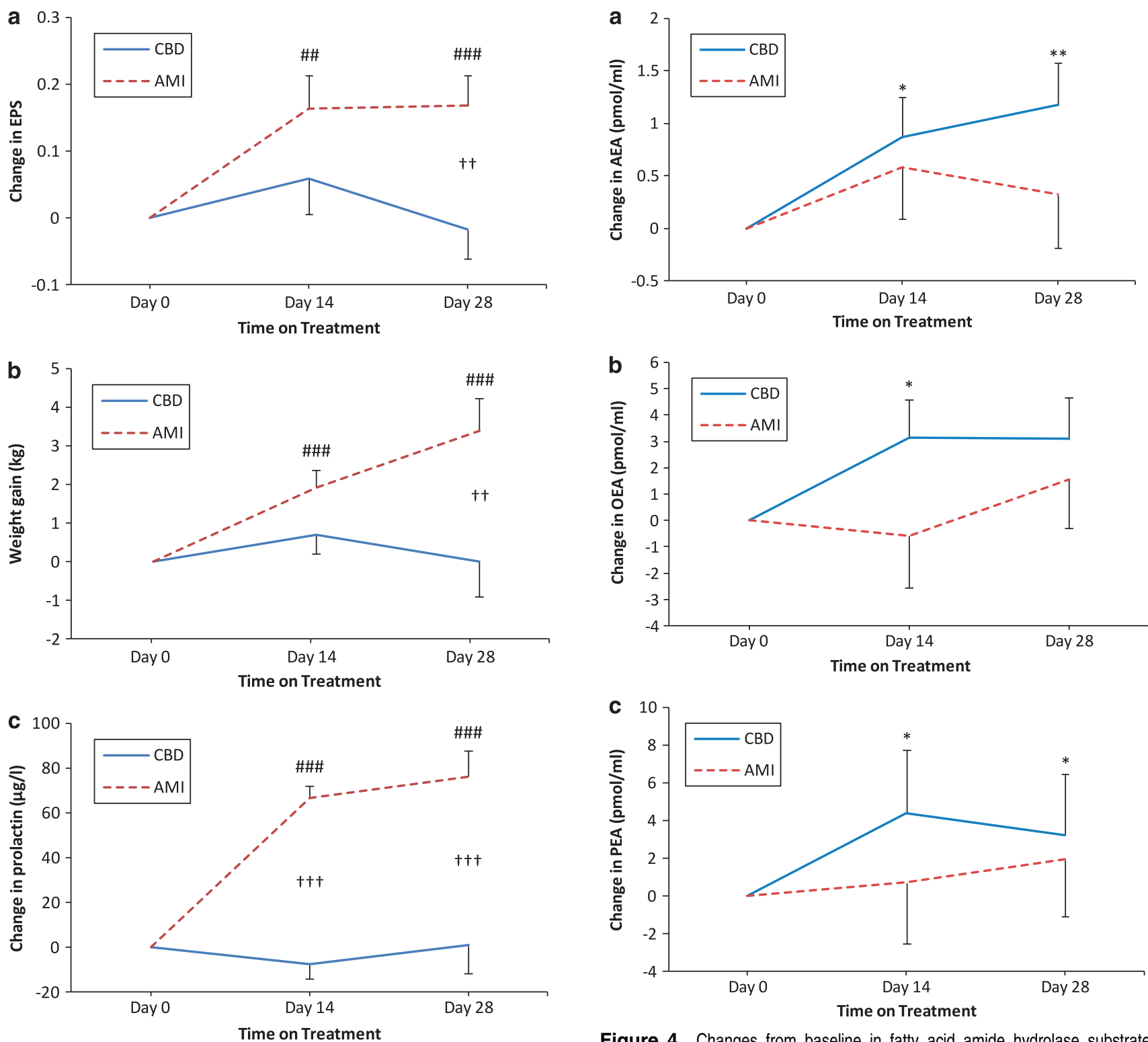

Figure 3 Changes from baseline in side effects determined using mixed effects repeated measures model analysis (adjusted for baseline). (a) Extrapyramidal Symptom Scale (EPS). (b) Weight gain. (c) Prolactin. Data show predicted means and s.e. at each weak. Statistical significance is calculated between groups $\left({ }^{\dagger} P \leqslant 0.05,{ }^{\dagger \dagger} P \leqslant 0.01\right.$ and $\left.{ }^{\dagger \dagger} P \leqslant 0.001\right)$ and vs baseline (that is, 0 ; ${ }^{*} \mathrm{CBD}$, $\mathrm{AM}$; ***/\#\#\# $P \leqslant 0.05,{ }^{* \star / \# \#} P \leqslant 0.01,{ }^{* / \#} P \leqslant 0.001$.

subcategories of symptoms of schizophrenia (Figures $2 \mathrm{~b}-\mathrm{d}$, Table 2). Comparison (modified intention-to-treat) of the clinical effects of amisulpride and cannabidiol revealed no relevant difference between the two treatments $(1.0,95 \%$ confidence interval -12.6 to $14.6, P=0.884$; Table 2); the confirmatory test of non-inferiority with $80 \%$ retention bound yielded a ratio of means 0.94 (CBD/AMI) with $95 \%$ confidence interval $0.55-1.59$. Thus non-inferiority seems highly plausible, but could not be demonstrated, $P=0.27$ (one-sided). Results were very similar using the per protocol set and/or the BPRS (Table 2). We found no difference in the proportion of responders $(\geqslant 20 \%$ improvement in PANSS total score) to each treatment (CBD 15/20, AMI 14/19, $P=1.000$ ).

Figure 4 Changes from baseline in fatty acid amide hydrolase substrates determined using mixed effects repeated measures model analysis (adjusted for baseline). (a) Anandamide (AEA) in serum. (b) Oleoylethanolamide (OEA) in serum. (c) Palmitoylethanolamide (PEA) in serum. Data show predicted means and s.e. at each weak. Statistical significance is calculated between groups $\left({ }^{\dagger} P \leqslant 0.05,{ }^{\dagger \dagger} P \leqslant 0.01\right.$ and $\left.{ }^{\dagger \dagger \dagger} P \leqslant 0.001\right)$ and vs baseline (that is, $0 ;{ }^{*} \mathrm{CBD}$,

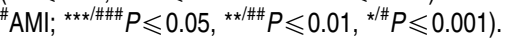

Furthermore, lorazepam co-medication did not significantly influence our results (Supplementary Figure 1). These results suggest that cannabidiol is as effective at improving psychotic symptoms as the standard antipsychotic amisulpride.

The use of antipsychotic drugs is associated with frequent side effects, which markedly influence acute compliance and long-term treatment adherence. These include motor disturbances (so-called extrapyramidal symptoms), weight gain and sexual dysfunction. Compared with amisulpride, we found that treatment with cannabidiol was associated with significantly fewer extrapyramidal symptoms $(P=0.006$; Figure 3a), less weight gain ( $P=0.010$; Figure $3 b)$, and lower prolactin increase-a predictor of galactorrhoea and sexual 

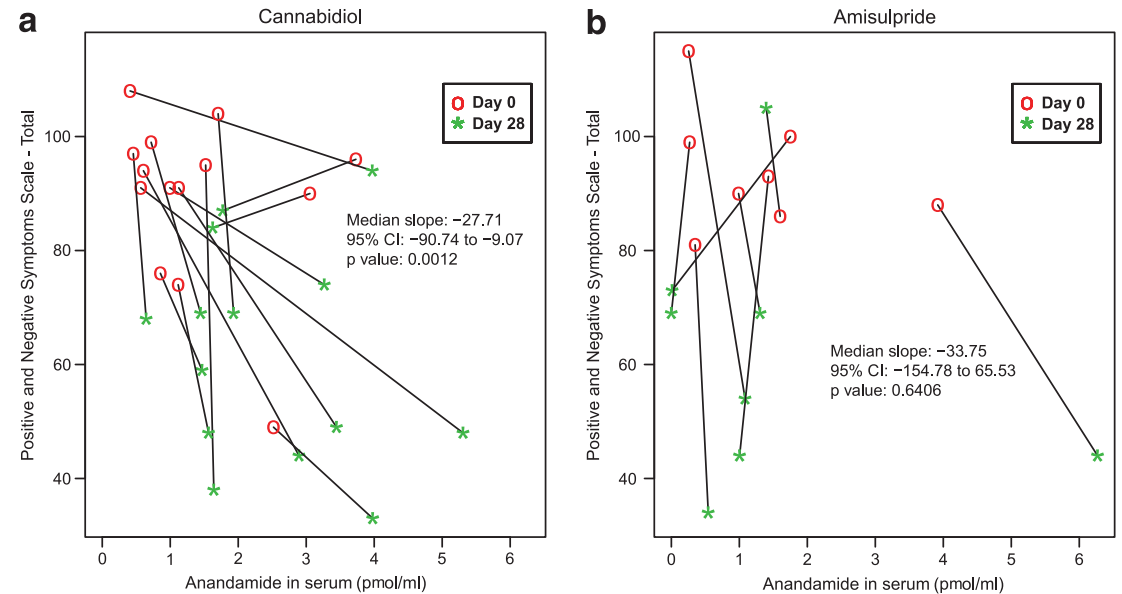

Figure 5 Association of change in anandamide in serum and change in the Positive and Negative Symptoms Scale total score in patients treated and observed per protocol. (a) Individual changes of patients treated with cannabidiol $(n=14)$. (b) Individual changes of patients treated with amisulpride $(n=8)$. $P$-values are from the Wilcoxon signed rank test of the null hypothesis that the distribution of slope is symmetric about zero.

dysfunction $(P<0.001$; Figure 3c). Furthermore, cannabidiol was well-tolerated (Supplementary Table 3 ) and did not significantly affect hepatic or cardiac functions.

Previous work has suggested that cannabidiol may protect anandamide from deactivation by interfering with $\mathrm{FAAH}$ activity 15 . We confirmed this result showing that cannabidiol inhibits FAAH in rat brain membranes with a median effective concentration of $8.6 \pm 0.2 \mu \mathrm{M}(n=12)$. We further found that cannabidiol, at a concentration that reduces FAAH activity by $\sim 50 \%(10 \mu \mathrm{M})$, does not significantly interact with a broad panel of neurotransmitter receptors that are relevant to schizophrenia, including dopamine, glutamate and serotonine. To determine whether treatment with cannabidiol reduces FAAH activity in our study subjects, we measured anandamide concentrations in serum before and after exposure to cannabidiol or amisulpride. Anandamide levels were higher in subjects exposed to cannabidiol than in those exposed to amisulpride (Figure 4a). Importantly, the serum levels of two additional FAAH substrates-the non-cannabimimetic lipid mediators palmitoylethanolamide (Figure 4b) and oleoylethanolamide (Figure 4c) - were also elevated in schizophrenic patients treated with cannabidiol, compared with those treated with amisulpride.

Next, to assess whether the ability to impair FAAH activity might contribute to the antipsychotic effects of cannabidiol, we investigated the relationship between changes in serum anandamide levels and psychotic symptoms (median slope analysis). We found a statistically significant association between increase in anandamide levels and decrease in psychotic symptoms in patients treated with cannabidiol $(P=0.0012)$. In contrast, no such association was found in patients treated with amisulpride $(P=0.64)$ (Figure 5). Moreover, no such relationship was apparent for serum oleoylethanolamide (median slopes: cannabidiol -0.051 / (pmol ml $\left.{ }^{-1}\right), P=1.00$, amisulpride $5.911 /\left(\mathrm{pmol} \mathrm{ml}^{-1}\right), P=0.30$ ) or serum palmitoylethanolamide (median slopes: cannabidiol $-3.81 /\left(\mathrm{pmol} \mathrm{ml}^{-1}\right), P=0.091$, amisulpride $-5.61 /\left(\mathrm{pmol} \mathrm{ml}^{-1}\right)$, $P=0.19$ ). These findings suggest the existence of a functional link between the antipsychotic effects of cannabidiol and its ability to inhibit anandamide degradation, though further research is needed to determine whether this link represents cause and effect.

\section{Discussion}

Our results provide evidence that the non-cannabimimetic constituent of marijuana, cannabidiol, exerts clinically relevant antipsychotic effects that are associated with marked tolerability and safety, when compared with current medications. Although a plethora of pharmacological mechanisms have recently been suggested relevant for the antipsychotic effect of cannabidiol ${ }^{31}$ the primary pharmacological mechanism through which cannabidiol exerts this antipsychotic effect in humans is unclear at present. However, the significant association observed in cannabidiol-treated patients between improvement of clinical symptoms and serum anandamide levels suggests that the ability of cannabidiol to inhibit the FAAH activity and enhance intrinsic anandamide signaling might be a functionally relevant component of its antipsychotic properties. Although only serum levels of anandamide were assessed in this study in comparison with cerebrospinal fluid samples, ${ }^{13,32}$ the systemic effect of cannabidiol on FAAH inhibition is highly likely to be reflected in this compartment. In addition, while serum values of endocannabinoids have been found less useful in early stages of schizophrenia, they have been reported valuable in more chronic cases. ${ }^{33,34}$ Our interpretation is supported by two sets of clinical data. First, in a relatively large cohort of antipsychotic-naïve schizophrenic patients $(n=47)$, cerebrospinal anandamide levels were found to be inversely correlated with psychotic symptoms. ${ }^{13}$ Second, highrisk subjects for psychosis ${ }^{35}$ who exhibited lower cerebrospinal levels of anandamide also showed a higher risk for transiting to frank psychosis. ${ }^{32}$ As is often the case in this type of study, we cannot exclude that cannabidiol may reduce psychotic symptoms through complementary or even alternative mechanisms to FAAH inhibition, including interactions with serotonin $5-\mathrm{HT}_{1 \mathrm{~A}}$ receptors, ${ }^{36}$ GPR55 receptors ${ }^{37}$ and transient receptor potential vanilloid-1 receptors. ${ }^{19}$ Nevertheless, 
our results do provide a rationale for additional clinical testing of selective FAAH inhibitors in schizophrenia.

\section{Conflict of interest}

The authors declare no conflict of interest.

Acknowledgements. This study was supported by grants from the Stanley Medical Research Institute (FML) and the National Institute on Drug Abuse (DP). The funding sources had no influence on the design of the study or the analysis and interpretation of the results. We acknowledge the contribution of Drs Frauke Schultze-Lutter and Stephan Ruhrmann to the protocol and design and of Drs Christian Mauss, Brit M Nolden, Tobias Buzello, Miriam A Neatby and Anita Haensel to the execution of the clinical part of this study. We are also grateful to Prof Andrea Giuffrida for his fruitful input during the course of this study.

1. Rogers DP, Goldsmith CA. Treatment of schizophrenia in the 21 st century: beyond the neurotransmitter hypothesis. Expert Rev Neurother 2009; 9: 47-54.

2. Piomelli D. The molecular logic of endocannabinoid signalling. Nat Rev Neurosci 2003; 4 873-884.

3. Leweke FM, Schneider U, Thies M, Münte TF, Emrich HM. Effects of synthetic $\Delta^{9}$ tetrahydrocannabinol on binocular depth inversion of natural and artificial objects in man. Psychopharmacology 1999; 142: 230-235.

4. D'Souza CD, Perry E, MacDougall L, Ammerman Y, Cooper T, Wu Y-T et al. The psychotomimetic effects of intravenous delta-9-tetrahydrocannabinol in healthy individuals: implications for psychosis. Neuropsychopharmacology 2004; 29: 1558-1572.

5. Morrison PD, Nottage J, Stone JM, Bhattacharyya S, Tunstall N, Brenneisen R et al. Disruption of frontal theta coherence by Delta(9)-tetrahydrocannabinol is associated with positive psychotic symptoms. Neuropsychopharmacology 2011; 36: 827-836.

6. D'Souza DC, Abi-Saab WM, Madonick S, Forselius-Bielen K, Doersch A, Braley G et al. Delta-9-tetrahydrocannabinol effects in schizophrenia: implications for cognition, psychosis, and addiction. Biol Psychiatry 2005; 57: 594-608

7. Henquet C, van Os J, Kuepper R, Delespaul P, Smits M, Campo JA et al. Psychosis reactivity to cannabis use in daily life: an experience sampling study. Br J Psychiatry 2010; 196: 447-453.

8. Scatton B, Sanger DJ. Pharmacological and molecular targets in the search for novel antipsychotics. Behav Pharmacol 2000; 11: 243-256.

9. Eggan SM, Hashimoto T, Lewis DA. Reduced cortical cannabinoid 1 receptor messenge RNA and protein expression in schizophrenia. Arch Gen Psychiatry 2008; 65: 772-784.

10. Meltzer HY, Arvanitis L, Bauer D, Rein W. Placebo-controlled evaluation of four novel compounds for the treatment of schizophrenia and schizoaffective disorder. Am J Psychiatry 2004; 161: 975-984.

11. Sanofi-Aventis. Efficacy and safety of AVE1625 as a co-treatment with antipsychotic therapy in schizophrenia (CONNECT). ClinicalTrials gov, May 11 2010; edn, vol. NCT00439634. US National Institute of Health, 2010.

12. Leweke FM, Giuffrida A, Wurster U, Emrich HM, Piomelli D. Elevated endogenous cannabinoids in schizophrenia. Neuroreport 1999; 10: 1665-1669.

13. Giuffrida A, Leweke FM, Gerth CW, Schreiber D, Koethe D, Faulhaber J et al. Cerebrospinal anandamide levels are elevated in acute schizophrenia and are inversely correlated with psychotic symptoms. Neuropsychopharmacology 2004; 29: 2108-2114.

14. Di Marzo V, Petrosino S. Endocannabinoids and the regulation of their levels in health and disease. Curr Opin Lipidol 2007; 18: 129-140.

15. Beltramo M, de Fonseca FR, Navarro M, Calignano A, Gorriti MA, Grammatikopoulos G et al. Reversal of dopamine $\mathrm{D}(2)$ receptor responses by an anandamide transport inhibitor. J Neurosci 2000; 20: 3401-3407.

16. Seillier A, Advani T, Cassano T, Hensler JG, Giuffrida A. Inhibition of fatty-acid amide hydrolase and $C B 1$ receptor antagonism differentially affect behavioural responses in normal and PCP-treated rats. Int J Neuropsychopharmacol 2010; 13: 373-386.

17. Petitet $F$, Jeantaud $B$, Reibaud M, Imperato A, Dubroeucq M-C. Complex pharmacology of natural cannabinoids: evidence for partial agonist activity of delta-9-tetrahydrocannabinol and antagonist activity of cannabidiol on rat brain cannabinoid receptors. Life Sci 1998; 63 : PL1-PL6.

18. Thomas A, Baillie GL, Phillips AM, Razdan RK, Ross RA, Pertwee RG. Cannabidiol displays unexpectedly high potency as an antagonist of $\mathrm{CB} 1$ and $\mathrm{CB} 2$ receptor agonists in vitro. Br J Pharmacol 2007; 150: 613-623.

19. Bisogno T, Hanus L, De Petrocellis L, Tchilibon S, Ponde DE, Brandi I et al. Molecular targets for cannabidiol and its synthetic analogues: effect on vanilloid VR1 receptors and on the cellular uptake and enzymatic hydrolysis of anandamide. Br J Pharmacol 2001; 134: 845-852.

20. Zuardi AW, Morais SL, Guimarães FS, Mechoulam R. Antipsychotic effect of cannabidiol. $J$ Clin Psychiatry 1995; 56: 485-486.

21. Zuardi AW, Hallak JE, Dursun SM, Morais SL, Faria Sanches R, Musty RE et al. Cannabidiol monotherapy for treatment-resistant schizophrenia. J Psychopharmacol 2006; 20: 683-686.

22. Leweke FM, Schneider U, Radwan M, Schmidt E, Emrich HM. Different effects of nabilone and cannabidiol on binocular depth inversion in man. Pharmacol Biochem Behav2000; 66: 175-181.

23. Bhattacharyya S, Morrison PD, Fusar-Poli P, Martin-Santos R, Borgwardt S, WintonBrown $T$ et al. Opposite effects of delta-9-tetrahydrocannabinol and cannabidiol on human brain function and psychopathology. Neuropsychopharmacology 2010; 35 : 764-774.

24. Schreiber D, Harlfinger S, Nolden BM, Gerth CW, Schömig E, Klosterkötter J et al. Determination of anandamide and other fatty acylethanolamides in human serum by electrospray tandem mass spectrometry. Anal Biochem 2007; 361: 162-168.

25. Giuffrida A, Rodriguez de Fonseca F, Piomelli D. Quantification of bioactive acylethanolamides in rat plasma by electrospray mass spectrometry. Anal Biochem 2000; 280: 87-93.

26. Danion JM, Rein W, Fleurot O. Improvement of schizophrenic patients with primary negative symptoms treated with amisulpride. Amisulpride Study Group. Am J Psychiatry 1999; 156: 610-616.

27. Hauschke D, Kieser M. Multiple testing to establish noninferiority of $k$ treatments with a reference based on the ratio of two means. Drug Inf J 2001; 35: 1247-1251.

28. van Os J, Burns T, Cavallaro R, Leucht S, Peuskens J, Helldin L et al. Standardized remission criteria in schizophrenia. Acta Psychiatr Scand 2006; 113: 91-95.

29. Committee for proprietary medicinal products (CPMP). Note for guidance on the clinical investigation of medicinal products in the treatment of schizophrenia. February 261998 ; CPMP/EWP/559/95, The European Agency for the Evaluation of Medicinal Products, London, 1998.

30. Leucht S, Pitschel-Walz G, Engel RR, Kissling W. Amisulpride, an unusual 'atypical' antipsychotic: a meta-analysis of randomized controlled trials. Am J Psychiatry 2002; 159: 180-190.

31. Izzo AA, Borrelli F, Capasso R, Di Marzo V, Mechoulam R. Non-psychotropic plant cannabinoids: new therapeutic opportunities from an ancient herb. Trends Pharmacol Sci 2009; 30: 515-527.

32. Koethe D, Giuffrida A, Schreiber D, Hellmich M, Schultze-Lutter F, Ruhrmann S et al. Anandamide elevation in cerebrospinal fluid in initial prodromal states of psychosis. $\mathrm{Br} \mathrm{J}$ Psychiatry 2009; 194: 371-372.

33. Potvin S, Kouassi E, Lipp O, Bouchard RH, Roy MA, Demers MF et al. Endogenous cannabinoids in patients with schizophrenia and substance use disorder during quetiapine therapy. J Psychopharmacol 2008; 22: 262-269.

34. De Marchi N, De Petrocellis L, Orlando P, Daniele F, Fezza F, Di Marzo V. Endocannabinoid signalling in the blood of patients with schizophrenia. Lipids Health Dis 2003; 2: 5-13.

35. Ruhrmann S, Schultze-Lutter F, Salokangas RK, Heinimaa M, Linszen D, Dingemans $P$ et al. Prediction of psychosis in adolescents and young adults at high risk: results from the prospective European prediction of psychosis study. Arch Gen Psychiatry 2010; 67: 241-251.

36. Russo E, Burnett A, Hall B, Parker K. Agonistic properties of cannabidiol at 5-HT1a receptors. Neurochem Res 2005; 30: 1037-1043.

37. Ryberg E, Larsson N, Sjogren S, Hjorth S, Hermansson NO, Leonova J et al. The orphan receptor GPR55 is a novel cannabinoid receptor. Br J Pharmacol 2007; 152: 1092-1101.

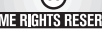
licensed under the Creative Commons Attribution-Noncommercial-No Derivative Works 3.0 Unported License. To view a copy of this license, visit http://creativecommons.org/licenses/by-nc-nd/3.0/

\section{Supplementary Information accompanies the paper on the Translational Psychiatry website (http://www.nature.com/tp)}

